\title{
OPEN LETTER TO EDITOR AND READERS \\ After more than sixty years we are still unclear whether LSD has a place in clinical psychiatry
}

\author{
Arthur Saniotis ${ }^{1,2}$ \\ ${ }^{1}$ Department of Anthropology, Ludwik Hirszfeld Institute of Immunology and Experimental Therapy, Polish Academy of Sciences, \\ Wroclaw, Poland; ${ }^{2}$ Biological Anthropology and Comparative Anatomy Research Unit, Adelaide Medical School, University of Ade- \\ laide, Australia
}

\section{Dear Editor,}

The use of the psychedelic lysergic acid diethylamide (LSD) has again provoked scientific debate over its efficacy and safety. In the 1950s-1960s LSD was used in psychotherapy for treating depression, anxiety related to terminal cancer, addiction, and pain. However, these studies were not conducted under current guidelines (Fuentes, Fonseca, Elices, Farré., \& Torrens, et al., 2020).

Given the enormity of studies conducted on LSD in psychotherapy the psychiatric community has yet to reach a consensus on its therapeutic value. As a way of fuelling this discussion a new systematic review identified 3668 papers on LSD out of which 11 papers were used (Fuentes et al., 2020). Despite the heterogeneity of the studies the

Correspondence: Arthur Saniotis, Department of Anthropology, Ludwik Hirszfeld Institute of Immunology and Experimental Therapy, Polish Academy of Sciences, Rudolfa Weigla St. 12, 53-114 Wroclaw, Poland; Biological Anthropology and Comparative Anatomy Research Unit, Adelaide Medical School, University of Adelaide, Australia.

E-mail: arthur.saniotis@hirszfeld.pl

Citation: Saniotis, A. (2020). After more than sixty years we are still unclear whether LSD has a place in clinical psychiatry. Research in Psychotherapy: Psychopathology, Process and Outcome, 23(2), 197198. doi: 10.4081 /ripppo.2020.464

Conflict of interest: The Author declare no potential conflict of interest.

Key words: Psychedelic based therapy; depressive disorders; neurobiological effects; psychedelic reaction.

Received for publication: 18 May 2020.

Accepted for publication: 6 July 2020.

This work is licensed under a Creative Commons Attribution NonCommercial 4.0 License (CC BY-NC 4.0).

${ }^{\circ}$ Copyright: the Author(s), 2020

Licensee PAGEPress, Italy

Research in Psychotherapy:

Psychopathology, Process and Outcome 2020; 23:197-198

doi:10.4081/ripppo.2020.464 review concluded that there is a potential for LSD as a therapeutic agent for treating individuals with alcoholic disorder. This is hardly novel. Published studies in the 1960's had made a similar conclusion (Ungerleider \& Andrysiak, 1981).

An interesting finding in the review points to the inadequacy of assessments and procedures or lack of control groups or appropriate statistical designs in most studies examined (Fuentes et al., 2020). This is reflected in the very few studies which were used in the review. In any case I concur with the review authors who highlight the difficulty in establishing satisfactory placebo control as well as monitoring psychological and objective experiences of LSD users when comparing them with other hallucinogens. This makes double blind studies very difficult to conduct (Fuentes et al., 2020). On this note, psychiatry is still uncertain whether the effects of single dose of LSD during psychotherapy are due to the action of psychedelics or by the intense psychological reaction (CarhartHarris et al., 2016).

Legal purchase of LSD is expensive and difficult to access. Hence, do the reported positive benefits of LSD therapy justify such expense and time investment for therapists? Psychiatrists really need to think about this. Are there alternatives to LSD which are therapeutic, cheaper and legal? The non-psychedelic, 4-Methylenedioxymethamphetamine (MDMA) is a potential candidate. Various studies have identified that MDMA based exposure-therapy (usually $125 \mathrm{mg}+\mathrm{a} 62.5$-mg top-up after 2 hours) can have therapeutic results in treating PostTraumatic Stress Disorder (PTSD) and alcoholism with major trauma (Nutt, 2019; Mithoefer, Wagner, Mithoefer, Jerome, \& Doblin, 2011; Mithoefer et al., 2018).

Some critics have argued whether it is the intensive discussion between therapist and patient, and not the drug alone, that vehicles the therapeutic process while others note that omitting therapy (not the drug) may work equally well (Nutt, 2019). Consequently, the use of nondrug follow-up sessions provide an opportunity to address both the value of the psychedelic sessions for both therapist and patient, as well as, better understanding psycho- 
logical mechanisms of LSD (Tupper, Wood, Yensen, \& Johnson, 2015).

This leads us to another clinical problem, that is, many patients suffering with depressive disorders are invariably on anti-depressants which may hinder the effect of LSD and other psychedelics (Nutt, 2019). For instance, selective serotonin reuptake inhibitors can desensitize 5-HT2A receptors thereby attenuating a psychedelic's effectiveness (Bonson, 1996). Consequently, should a patient stop taking anti-depressants for the duration of psychedelic based therapy which could produce withdrawal reactions and risk worsening his/her mental illness? (Nutt, 2019). Again, this is unclear. Even if LSD based sessions do not require a long-term time period do possible economic benefits outweigh current uncertainties regarding the drug's effect at a neurobiological level. Our knowledge of the neurobiological effects of psychedelics is still inadequate (Gasser, Kirchner, \& Passie, 2015).

Finally, many psychiatrists are either unfamiliar or sceptical of previous clinical LSD research. Therefore, how do we encourage the younger generation of psychiatrists in using LSD based therapy considering the aforementioned challenges? While this short letter only scrapes the surface of psychedelic research the question whether LSD has a place in clinical psychiatry is still uncertain.

\section{References}

Bonson, K. (1996). Chronic administration of serotonergic antidepressants attenuates the subjective effects of LSD in humans. Neuropsychopharmacology, 14, 425-436. doi: 10.1016/0893- 133X(95)00145-4.
Carhart-Harris, R.L., Bolstridge, M., \& Rucker. J., et al. (2016). Psilocybin with psychological support for treatment-resistant depression: an open-label feasibility study. Lancet Psychiatry, 3(7), 619-27. doi.org/10.1016/ S2215-0366(16) 30065-7

Fuentes, J.J., Fonseca, F., Elices, M., Farré., M., \& Torrens, M. (2020) Therapeutic Use of LSD in Psychiatry: A Systematic Review of Randomized-Controlled Clinical Trials. Front. Psychiatry, 10, 943. doi: 10.3389/fpsyt.2019.00943

Gasser, P., Kirchner, K., and Passie, T. (2015). LSD-assisted psychotherapy for anxiety associated with a life-threatening disease: a qualitative study of acute and sustained subjective effects. Journal of Psychopharmacology, 29(1), 57-68. doi: 10.1177/0269881114555249

Mithoefer, M.C., Wagner, T.M., Mithoefer, A.T., Jerome, L., \& Doblin, R. (2011). The safety and efficacy of $\pm 3,4$-methylenedioxymethamphetamine-assisted psychotherapy in subjects with chronic, treatment-resistant posttraumatic stress disorder: the first randomized controlled pilot study. Journal of Psychopharmacology, 25(4), 439-452. doi: 10.1177/ 0269881110378371

Mithoefer, M.C., Mithoefer, A.T., Feduccia. L., et al. (2018). MDMA-assisted psychotherapy for post-traumatic stress disorder in military veterans, firefighters, and police officers: a randomised, double-blind, dose-response, phase 2 clinical trial. Lancet Psychiatry, 55(6), 486-497. doi.org/10.1016/ S2215-0366(18)30135-4

Nutt, D. (2019). Psychedelic drugs - a new era in psychiatry? Dialogues in Clinical Neuroscience, 21(2), 139-147. doi:10.31887/DCNS.2019.21.2/dnutt

Tupper, K.W., Wood, E., Yensen, R., \& Johnson, M.W. (2015). Psychedelic medicine: a re-emerging therapeutic paradigm. CMAJ, 187(14), 1054-1059. doi:10.1503/cmaj.141124

Ungerleider, J.T., \& Adrysiak, T. (1981). Therapeutic uses of the drugs of abuse. Annals of the New York Academy of Sciences, 362, 173-180. doi.org/10.1111/j.1749-6632.1981.tb12805.x

\section{CALL FOR PAPERS}

\section{RESEARCH IN PSYCHOTHERAPY: PSYCHOPATHOLOGY, PROCESS AND OUTCOME}

Anyone interested in answering this Open Letter is free to do so by submitting the response and considerations to our Journal, indicating as title:

Reply: Saniotis, A. (2020). After more than sixty years we are still unclear whether LSD has a place in clinical psychiatry. Research in Psychotherapy: Psychopathology, Process and Outcome, 23(2), 197-198. doi: 10.4081/ ripppo. 2020.464

For questions feel free to contact the Editor in Chief, Dr. Silvia Salcuni: silvia.salcuni@unipd.it or the Journal Editor, Dr. Francesca Savio: francesca.savio@pagepress.org 